\title{
Gastroepiploic vascularized lymph node transfer for the treatment of extremity lymphedema: comparison between middle and distal inset
}

\author{
Oscar J. Manrique ${ }^{1,2 \#}$, Samyd Said Bustos ${ }^{1,2 \#}$, Trishul Kapoor ${ }^{3}$, Jason Lin ${ }^{4}$, Pedro Ciudad \\ Antonio J. Forte ${ }^{2,6}$, Gabriel Del Corral ${ }^{7}$, Maria Mani ${ }^{8}$, Michele Maruccia ${ }^{9}$, Andre Terzic ${ }^{2}$ \\ ${ }^{1}$ Division of Plastic and Reconstructive Surgery, ${ }^{2}$ Center for Regenerative Medicine, ${ }^{3}$ Department of Surgery, Mayo Clinic, Rochester, MN, USA; \\ ${ }^{4}$ Mayo Clinic Alix School of Medicine, Rochester, MN, USA; ${ }^{5}$ Department of Plastic, Reconstructive and Burn Surgery, Arzobispo Loayza National \\ Hospital, Lima, Peru; ${ }^{6}$ Division of Plastic Surgery, Mayo Clinic, Jacksonville, FL, USA; ${ }^{7}$ MedStar Plastic and Reconstructive Surgery, Georgetown \\ University Hospital, Washington D.C., USA; ${ }^{8}$ Department of Plastic Surgery, Uppsala Universitet, Uppsala, Sweden; ${ }^{9}$ Division of Plastic and \\ Reconstructive Surgery, Department of Emergency and Organ Transplantation, University of Bari Aldo Moro, Bari, Italy \\ Contributions: (I) Conception and design: OJ Manrique, SS Bustos, T Kapoor, J Lin; (II) Administrative support: OJ Manrique, P Ciudad, AJ Forte; \\ (III) Provision of study materials or patients: OJ Manrique; (IV) Collection and assembly of data: OJ Manrique, SS Bustos, T Kapoor, J Lin; (V) Data \\ analysis and interpretation: OJ Manrique, SS Bustos, T Kapoor, J Lin; (VI) Manuscript writing: All authors; (VII) Final approval of manuscript: All \\ authors. \\ \#These authors contributed equally to this work. \\ Correspondence to: Oscar J. Manrique, MD, FACS. Division of Plastic and Reconstructive Surgery, Mayo Clinic, Rochester, MN, USA. \\ Email: oscarj.manrique@gmail.com.
}

Background Middle and distal insets of gastroepiploic vascularized lymph node transfer (GE-VLNT) for extremity lymphedema have been described. However, there has been no prior comparison of surgical or patient-reported outcomes between these techniques. We analyzed the outcomes between both insets in patients with extremity lymphedema.

Methods: Retrospective review of patients with extremity-lymphedema who underwent GE-VLNT. Two groups were analyzed: middle and distal recipient inset. We analyzed 6-month surgical and patient-reported outcomes using the Lymphedema Life Impact Scale-v2 (LLISv2) and scar satisfaction utilizing the Patient Scar Assessment Questionnaire (PSAQ).

Results: Between 2017 and 2019, 26 patients with stage II unilateral extremity lymphedema underwent laparoscopically-harvested GE-VLNT (13 distal and 13 middle inset). There were no differences in patient demographics between groups. Mean hospital stay for patients with upper extremity lymphedema was 1.3 vs. 4.0 days $(\mathrm{P}<0.05)$, and for lower extremity lymphedema was 1.0 vs. 4.5 days $(\mathrm{P}<0.05)$, middle vs. distal inset, respectively. Mean return to daily activities for patients with upper extremity lymphedema was 13.4 vs. 33.4 days $(\mathrm{P}<0.05)$, and for lower extremity lymphedema was 16.0 vs. 29.5 days $(\mathrm{P}<0.05)$, middle vs. distal inset, respectively. Both middle and distal inset showed significant mean excess volume reduction at 6 months postoperatively for both upper and lower extremity lymphedema (upper extremity: middle inset $23.3 \%$, distal inset: $22.0 \%$; lower extremity: middle inset $23.3 \%$ and distal inset $13.3 \%$ ). LLISv2 scores showed improved functional outcomes postoperatively in both upper and lower extremity lymphedema with both insets. Scar satisfaction with appearance and symptoms was higher with middle inset $(\mathrm{P}<0.05)$.

Conclusions: GE-VLNT is an effective surgical treatment for extremity lymphedema. The middle placement showed shorter hospital stay, early return to work and higher patient satisfaction.

Keywords: Lymphedema; breast cancer lymphedema; lymph nodes; surgical flaps; microsurgery

Submitted Nov 16, 2019. Accepted for publication Dec 12, 2019.

doi: 10.21037 /gs.2020.02.10

View this article at: http://dx.doi.org/10.21037/gs.2020.02.10

(c) Gland Surgery. All rights reserved. 


\section{Introduction}

Lymphedema is a debilitating disease that affects up to 250 million people worldwide (1). In the United States, lymphedema is typically caused by oncologic resection of axillary or groin lymph nodes following breast or pelvic cancer surgeries, respectively $(2,3)$. Specifically, in patients who have undergone axillary lymph node dissection following mastectomies $(4,5)$, the incidence of extremity lymphedema ranges from $9 \%$ to $41 \%$. For lower extremity lymphedema following gynecologic cancer, the reported incidence ranges from 0 to $70 \%(6,7)$, depending on the type of cancer and treatment. These patients often suffer from symptoms like swelling, pain, and recurrent cellulitis that significant impacts their quality of life $(2,3,8-10)$.

Chronic lymphedema is typically managed through a multidisciplinary approach, mainly focused on complex decongestive therapy (11). Due to the recent advancements in microsurgical and supermicrosurgical techniques, physiological reconstructive options have become increasingly popular in the treatment of severe lymphedema $(2,12,13)$. Vascularized lymph node transfer (VLNT) is a surgical option that has become popular due to its success in limb volume reduction, particularly in patients refractory to conservative treatment and advanced stages of lymphedema such as stages II and III ISL (5,14-18).

The greater omentum offers great possibilities for tissue healing in complex disease (2). The transfer of vascularized gastroepiploic lymph nodes has become a robust surgical treatment option for patients with advanced extremity lymphedema. The use of omentum flaps in the management of lymphedema was first reported in 1967, and the first series of omental lymph node transfers to treat lymphedema was performed in $1990(2,14,19,20)$. Since then, a number of studies have looked into modifications and improvements of the technique, including minimally-invasive harvest of free omentum (gastroepiploic) vascularized lymph node flaps $(2,12,17,21-26)$.

Middle (anterior thigh or antecubital fossa) and distal (medial ankle or volar wrist) insets of vascularized lymph node flaps for the treatment of extremity lymphedema have been described $(17,27,28)$. To our knowledge, this is the first study comparing mid-inset $v s$. distal recipient site for gastroepiploic vascularized lymph node transfer (GE-VLNT) in patients with extremity lymphedema. In this study, we assessed and compared surgical and patientreported outcomes between middle and distal inset of the GE-VLNT in patients with advanced extremity lymphedema.

\section{Methods}

After approval by the Institutional Review Board (IRB No. 18-003248), a retrospective chart review of patients with extremity lymphedema who underwent GE-VLNT was performed. All patients prior to surgery underwent evaluation by a lymphedema therapist with refractory management for a minimum of 2 years and secondary causes of lymphedema. All included patients had been diagnosed with stage II International Society of Lymphedema (ISL) lymphedema (11). We included patients with a clinical and radiologic (lymphoscintigraphy) diagnosis of lymphedema. Patients with open wounds, skin infections, confirmed cancer recurrence or distant metastases, as well as patients who underwent other surgical procedures to treat lymphedema were excluded from this study.

We identified and analyzed two groups depending on the recipient site of the transferred lymph node flap: middle buried insets $v s$. distal insets. We documented patient demographic characteristics of the two groups and recorded pre and postoperative clinical photographs at 6 months postoperatively. In addition, we evaluated postoperative complications, and surgical outcomes including hospital length of stay, return to daily activities, and excess volume reduction at 6 months postoperatively. To calculate the volume of each limb, the Partial Frustum Model (PFM) (29) was used by means of the summation of truncated cones $10 \mathrm{~cm}$ in length. Most upper extremities had six measurements and lower extremities had nine. To calculate the excess volume, we compared the percentage of volume difference between the affected and non-affected limb. To evaluate the excess volume reduction, we calculated the difference between excess volumes pre and postoperatively. In addition, lymphoscintigraphy preoperatively and at 1 year postoperative was also recorded. Following intradermal injection of radiotracer into the lower extremities, serial planar images of the body were obtained at 1, 3 and 6 hours in the posterior and anterior view.

Patient-reported outcomes for life impact and scar satisfaction were assessed. We used the Lymphedema Life Impact Scale version 2 (LLISv2) (30) both pre and at 6 -month postoperatively. The LLISv2 is a validated 18 -item questionnaire that provides additional accuracy in detecting impairment and treatment outcomes in patients with lymphedema (30). It consists of three domains: physical, psychosocial and functional. Each item is scored from 0 to 4 
(0-no interference, 4-interferes completely). In addition, the satisfaction module of the Patient Scar Assessment Questionnaire (PSAQ) (31) was utilized to assess patientreported outcomes of satisfaction with their scarring. Each item consists of a set of four-point scale (1-very satisfied, 4-very dissatisfied). Data were compared and analyzed between both groups.

\section{Surgical technique}

The gastroepiploic lymph node flap is harvested laparoscopically according to the procedure previously

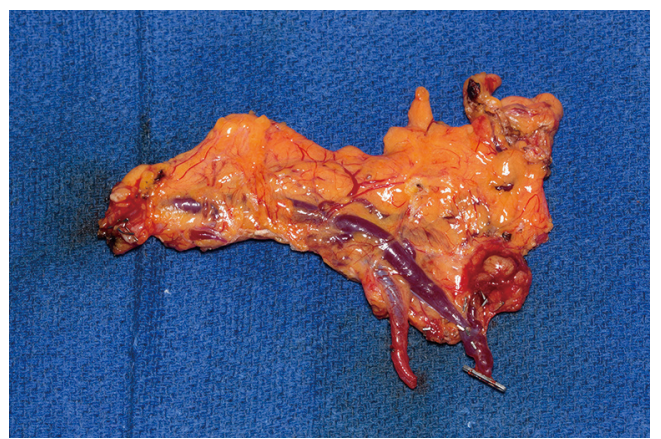

Figure 1 Gastroepiploic vascularized lymph node flap. described and published (24). Figure 1 shows the gastroepiploic flap and Figure 2 shows its inset in diverse sites. The location of the flap inset is determined by patient choice after discussing with the surgeon.

For the distal upper extremity inset, a skin flap is raised in an "L-shaped" fashion from the volar aspect of the wrist. The superficial branch of the radial artery and venae comitantes are used as recipient vessels. A split-thickness skin graft is harvested to avoid tension during closure of the GE-VLNT.

For the middle upper extremity inset, a "lazy S-shaped" incision is performed immediately below the antecubital fossa with the proximal $\mathrm{S}$ aspect favoring the radial site in order to capture the radial recurrent artery and venae comitantes. Dissection is carried down to the fascia making sure to preserve all the cutaneous veins and nerves. The brachioradialis muscle is retracted radially to expose the radial recurrent pedicle. One or two venae comitantes are identified and dissected. Once the recipient vessels are adequately exposed, microsurgical anastomoses are performed and primary skin closure without tension is done.

For the distal lower extremity inset, a straight incision is performed posterior to the medial malleolus. Dissection is carried down in order to expose the posterior tibial vessels.
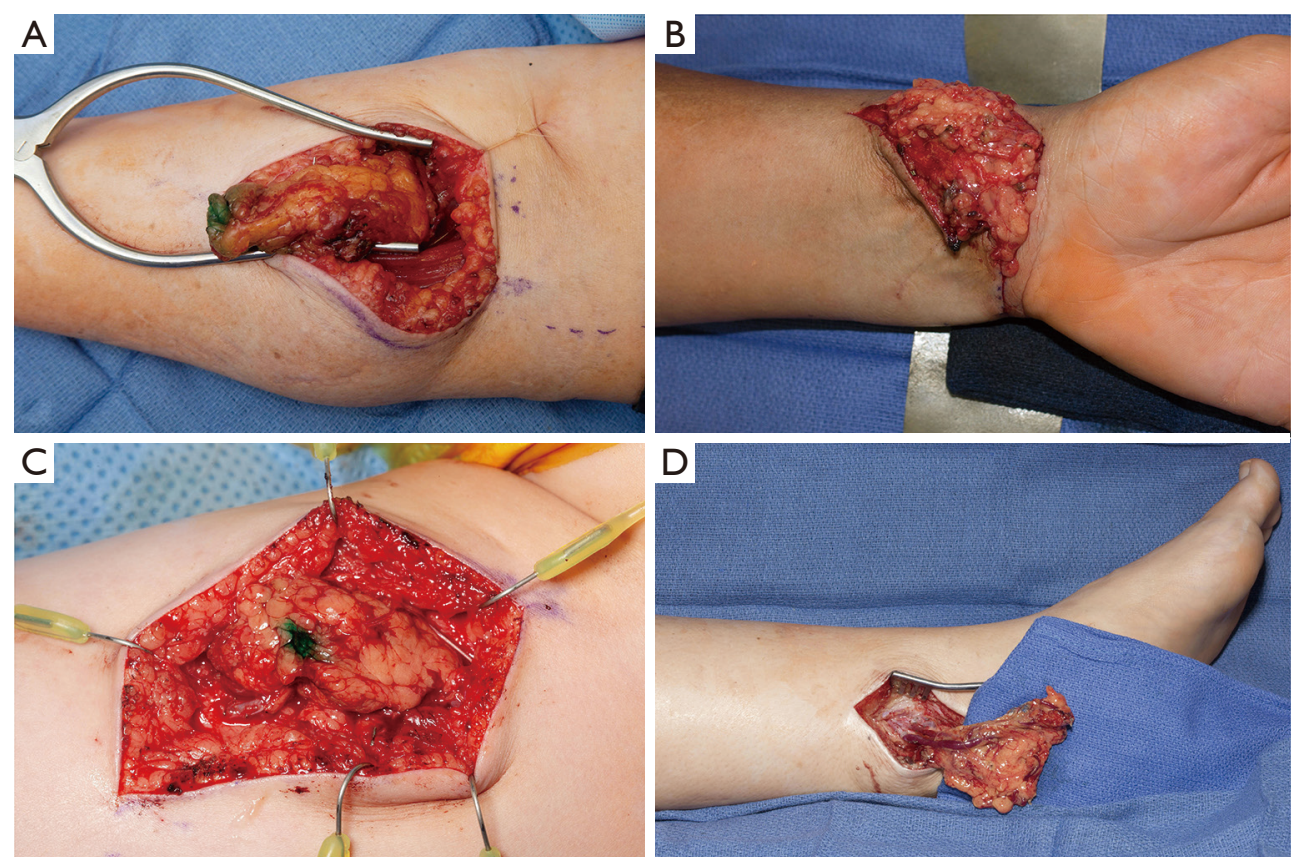

Figure 2 Flap inset surgical technique. (A) Volar middle flap inset in upper extremity; (B) volar distal flap inset in upper extremity; (C) anterior middle flap inset in lower extremity; (D) medial distal flap inset in lower extremity. 
Table 1 Characteristics of patients with extremity lymphedema who underwent gastroepiploic vascularized lymph node flap transfer

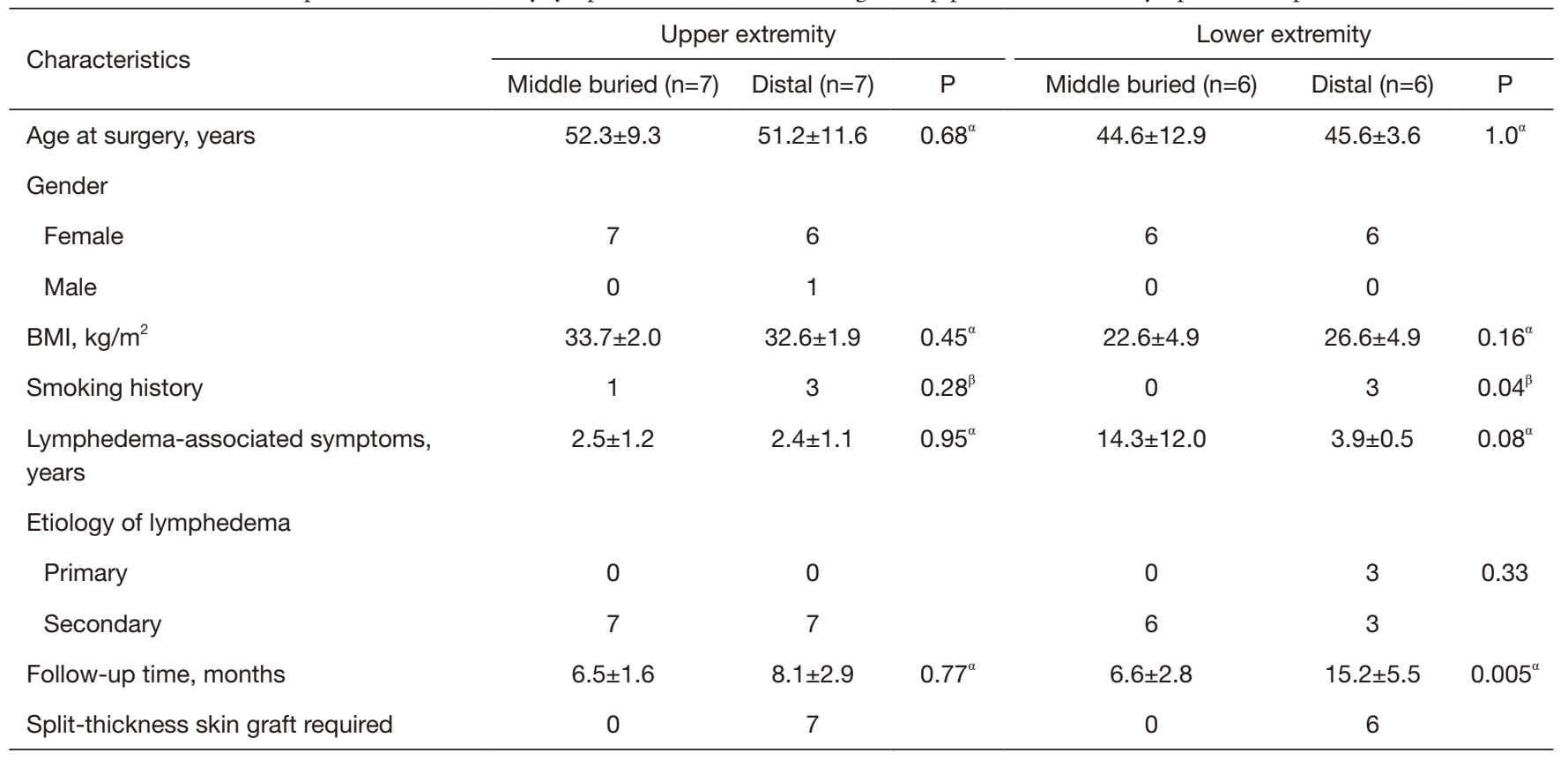

Data presented as mean and standard deviation. ${ }^{a}, \mathrm{P}$ value obtained comparing the median of the two groups using the Wilcoxon rank sum test; ${ }^{\beta}$, $\mathrm{P}$ value obtained comparing the proportions of the two groups using the Fisher's exact test.

In cases where the donor vessels do not match the recipient vessels, the dissection is performed more distal in order to identify the medial and lateral plantar arteries with venae comitantes. After appropriate exposure, microsurgical anastomoses are performed. Lastly, the wound is covered with a split-thickness skin graft harvested from the ipsilateral thigh.

For the mid-thigh inset, an $8 \mathrm{~cm}$ straight incision is performed over the mid-third of the anterior thigh. The dissection is carried to expose the descending branch of the lateral femoral circumflex vessels. Finally, the flap is placed and microsurgical anastomosis is performed. A small recipient bed is created in order to perform a tension-free primary skin closure.

Intraoperatively, Doppler signal was used in all cases to confirm adequate flap perfusion.

\section{Statistical analysis}

Statistical significance for differences between groups was analyzed using $\mathrm{JMP}^{\mathrm{O}}$ version 13 (SAS Institute Inc., Cary, NC, USA, 1989-2019). Fisher's exact tests were used to compare categorical variables. Either $t$-tests or Wilcoxon rank sum tests were used to compare continuous variables.
Paired $t$-tests were used to evaluate mean differences between groups. Statistical significance level was set at $\mathrm{P}<0.05$.

\section{Results}

Between 2017 and 2019, a total of 26 patients (25 females, 1 male). All flaps were harvested laparoscopically. All patients were ISL stage II. The mean age was $48.3 \pm 10.0$ years and mean BMI was $28.7 \pm 5.9 \mathrm{~kg} / \mathrm{m}^{2}$. Twenty-two $(84.6 \%)$ patients had a history of previous lymph node dissection. Vascularized lymph nodes were transferred distally in 13 $(50.0 \%)$ patients and proximally in $13(50.0 \%)$ patients. Table 1 shows the patient characteristics by upper and lower extremity. All patients with a distal GE-VLNT required skin grafting. Of these, 5 patients ( 3 in the upper extremity and 2 in the lower extremity group) experienced partial skin graft loss. None of the middle buried-transferred lymph node flaps required skin grafting and as a result, the wound was closed primarily.

A statistically significant difference was found for the average length of hospital stay between middle $v$ s. distal insets for both upper and lower extremity lymphedema groups. Patients who had middle inset were discharged 
Table 2 Surgical outcomes in patients with extremity lymphedema who underwent gastroepiploic vascularized lymph node flap transfer

\begin{tabular}{|c|c|c|c|c|c|c|}
\hline Characteristics & \multicolumn{3}{|c|}{ Upper extremity } & \multicolumn{3}{|c|}{ Lower extremity } \\
\hline Hospital stay, days & $1.3 \pm 0.5$ & $4.0 \pm 0.8$ & $0.0013^{*}$ & $1.0 \pm 0.2$ & $4.5 \pm 0.6$ & $0.002^{*}$ \\
\hline Return to daily activities, days & $13.4 \pm 0.5$ & $33.4 \pm 3.9$ & $0.003^{*}$ & $16 \pm 2.2$ & $29.5 \pm 1.6$ & $0.004^{*}$ \\
\hline Preoperative control limb volume, $\mathrm{L}$ & $2.9 \pm 0.7$ & $2.5 \pm 0.3$ & & $6.6 \pm 1.1$ & $8.8 \pm 0.3$ & \\
\hline Preoperative excess volume, $\%$ & $39.8 \pm 4.1$ & $35.5 \pm 17.0$ & & $57.0 \pm 17.6$ & $21.6 \pm 5.0$ & \\
\hline Postoperative control limb volume, L & $2.8 \pm 0.4$ & $2.9 \pm 0.2$ & & $6.6 \pm 1.1$ & $8.8 \pm 0.2$ & \\
\hline Postoperative affected limb volume, L & $3.2 \pm 0.3$ & $3.4 \pm 0.4$ & & $8.8 \pm 0.8$ & $9.5 \pm 0.9$ & \\
\hline Postoperative excess volume, $\%$ & $16.5 \pm 6.4$ & $13.5 \pm 8.5$ & & $33.7 \pm 8.2$ & $8.3 \pm 8.0$ & \\
\hline
\end{tabular}

Data presented as mean and standard deviation. *, statistically significant; ${ }^{\alpha}, \mathrm{P}$ value obtained comparing the median of the two groups using the Wilcoxon rank sum test; ${ }^{\beta}, \mathrm{P}$ value obtained by comparing the median differences (pre and postoperatively excess volume) using the Wilcoxon signed rank test; ${ }^{\circ}$, obtained from the difference between pre and postoperative excess volumes. Excess volume was calculated as the percentage of excess volume in the affected limb compared with the unaffected limb.

3 days earlier, on average, compared to patients who underwent distal inset $(\mathrm{P}<0.05)$. Table 2 shows the surgical outcomes of patients with extremity lymphedema by extremity and inset location. On average, patients with upper extremity lymphedema returned to daily activities in $13.4 \pm 0.5$ vs. $33.4 \pm 3.9$ days for the middle vs. distal inset groups, respectively $(\mathrm{P}=0.003)$. Patients with lower extremity lymphedema returned to daily activities in $16 \pm 2.2$ vs. 29.5 \pm 1.6 days for the middle $v s$. distal inset groups, respectively $(\mathrm{P}=0.004)$.

Pre and postoperative limb volume and excess volume reduction at 6 months postoperatively are also shown in Table 2. Both middle and distal inset groups for upper and lower extremity lymphedema patients showed a statistically significant excess volume reduction. Patients with upper extremity lymphedema who underwent middle inset showed a mean excess volume reduction of $23.3 \% \pm 5.1 \%$, and patients who underwent distal inset showed a mean excess volume reduction of $22.0 \% \pm 10.0 \%$. Patients with lower extremity lymphedema who underwent middle inset showed a mean excess volume reduction of $23.3 \% \pm 9.4 \%$, and patients who underwent distal inset showed a mean excess volume reduction of $13.3 \% \pm 3.3 \%$. However, no statistically significant difference was found when middle and distal insets were compared to each other. Figures 3-6 show pre and postoperative images of patients with extremity lymphedema that underwent GE-VLNT. Thirteen patients had 1-year postoperative lymphoscintigraphy, which showed new focal uptake corresponding to the transferred lymph nodes, improved radiotracer transit time and greater avidity compared to preoperative lymphoscintigraphic studies in most patients. However, an abnormal dermal-pattern lymphatic drainage was persistent in two patients: one with mid-inset in the lower extremities and one with distal inset in lower extremities.

Both middle and distal inset groups showed improvement in their physical, psychosocial and functional outcomes, but no difference was found when the groups were compared to each other (Tables 3,4). Scar satisfaction with both, appearance and symptoms, was found to be higher for the middle group compared with the distal inset group for both patients with upper and lower extremity lymphedema.

\section{Discussion}

This study retrospectively evaluated our clinical experience with vascularized lymph node flap transfer in patients with extremity lymphedema, and reaffirmed the effectiveness of these flaps. As the different surgical options continue to advance, opportunities for new VLNTs donor sites are also being investigated. Some of the traditional sites for lymph node harvest include the groin, supraclavicular, and axillary 

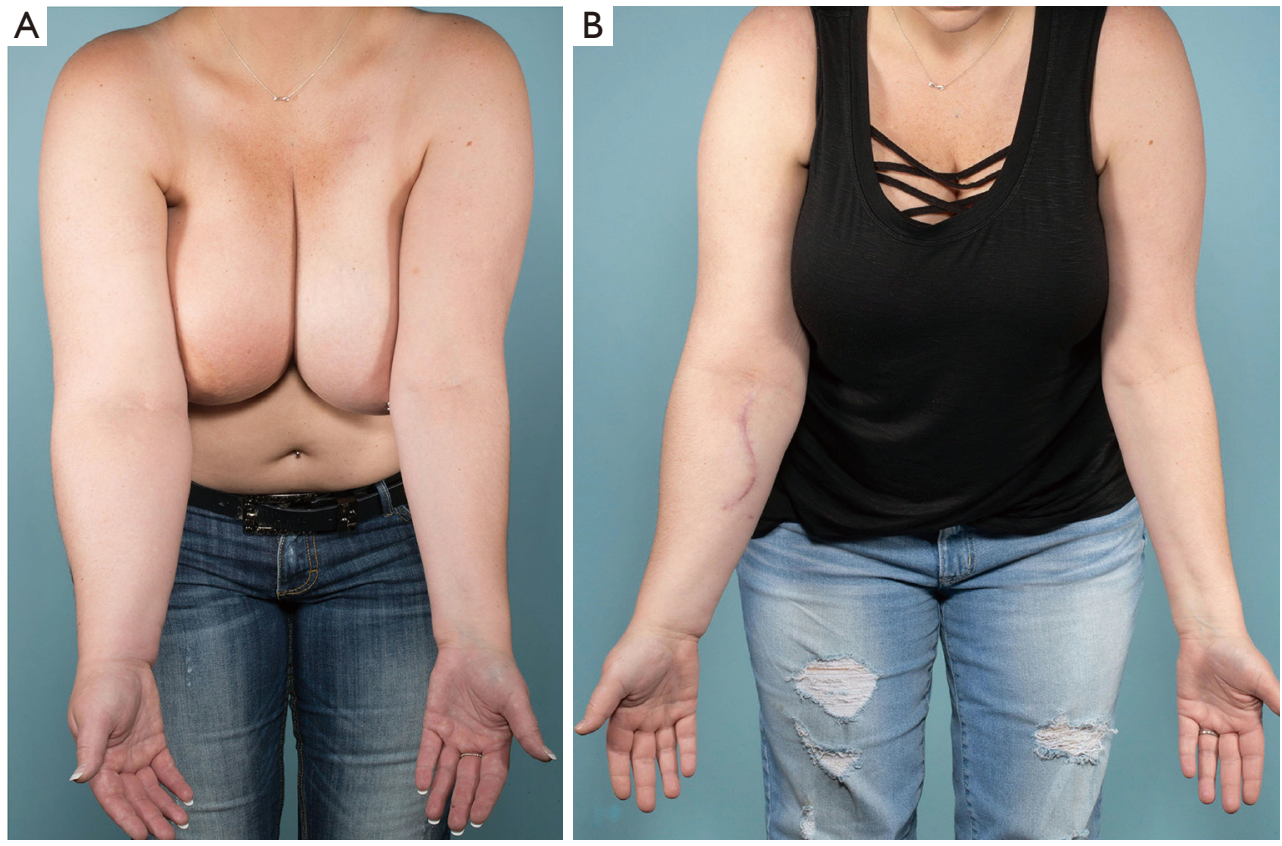

Figure 3 Volar middle inset pre and postoperatively in a 39-year-old patient with upper extremity lymphedema. (A) Preoperative; (B) 6 months postoperative shows an excess volume reduction of $28 \%$.
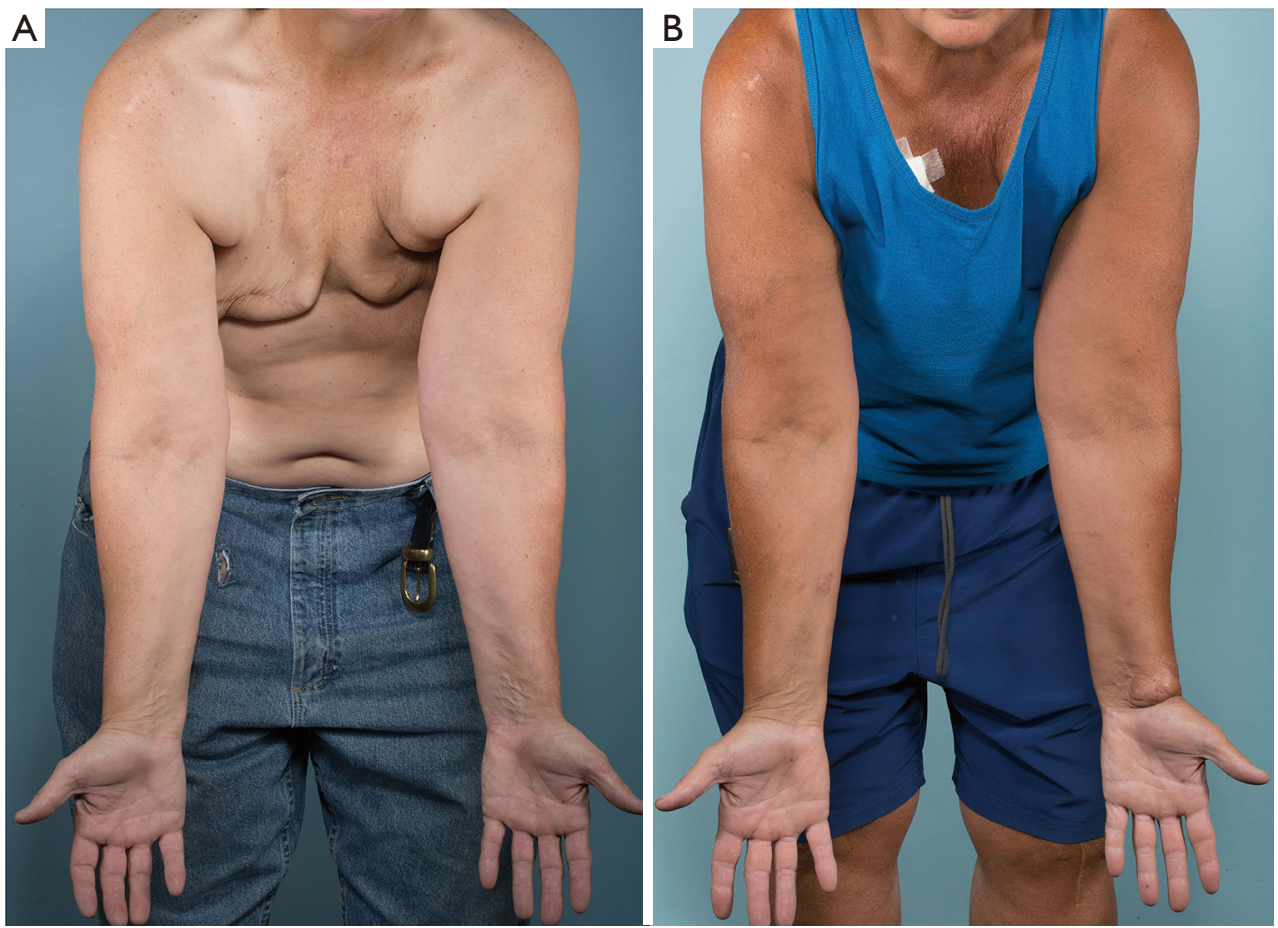

Figure 4 Volar distal inset pre and postoperatively in a 49-year-old patient with upper extremity lymphedema. (A) Preoperative; (B) 6 months postoperative shows an excess volume reduction of $20 \%$. 

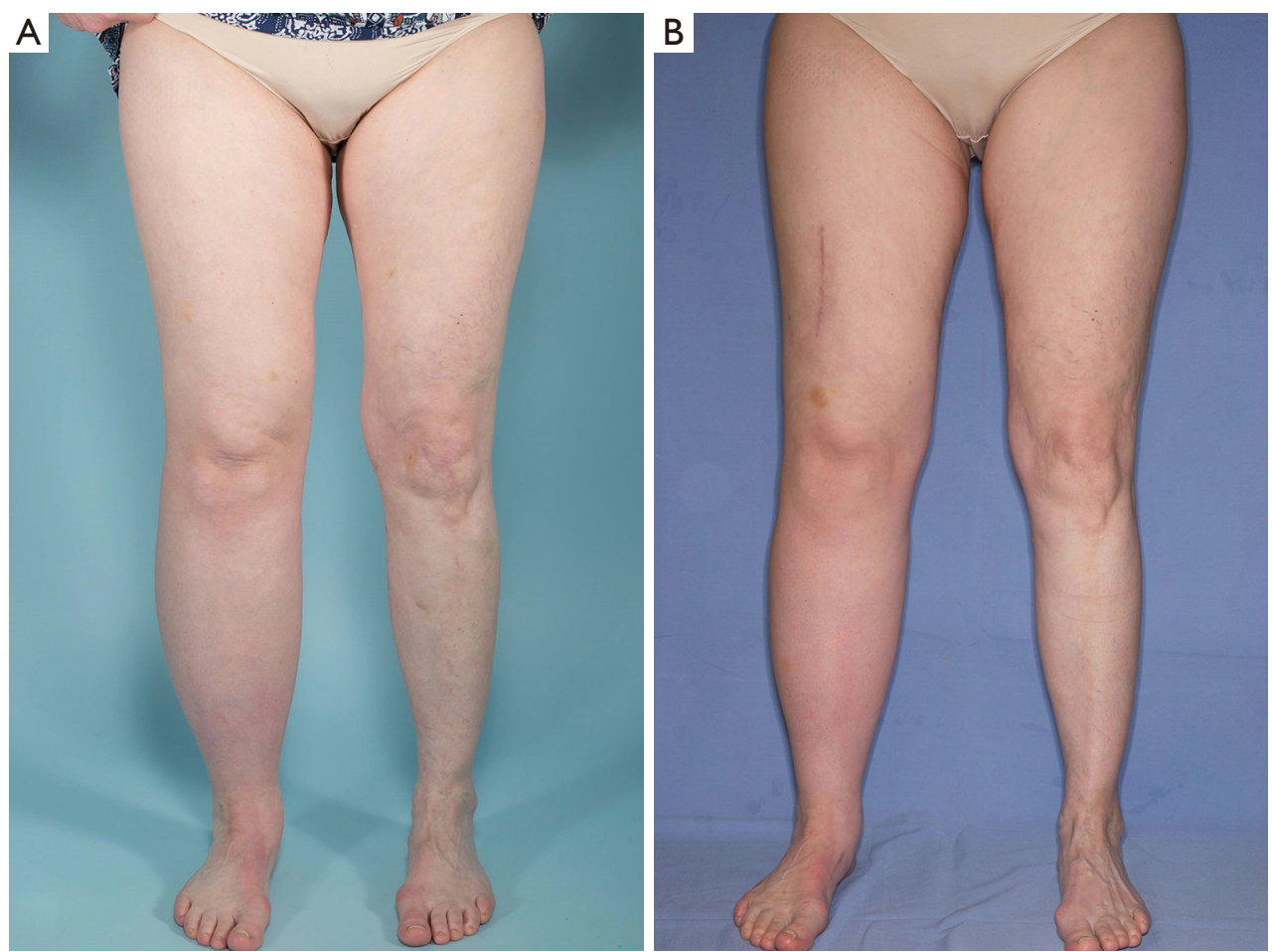

Figure 5 Anterior middle inset pre and postoperatively in a 37-year-old patient with lower extremity lymphedema. (A) Preoperative; (B) 6 months postoperative shows an excess volume reduction of $28 \%$.
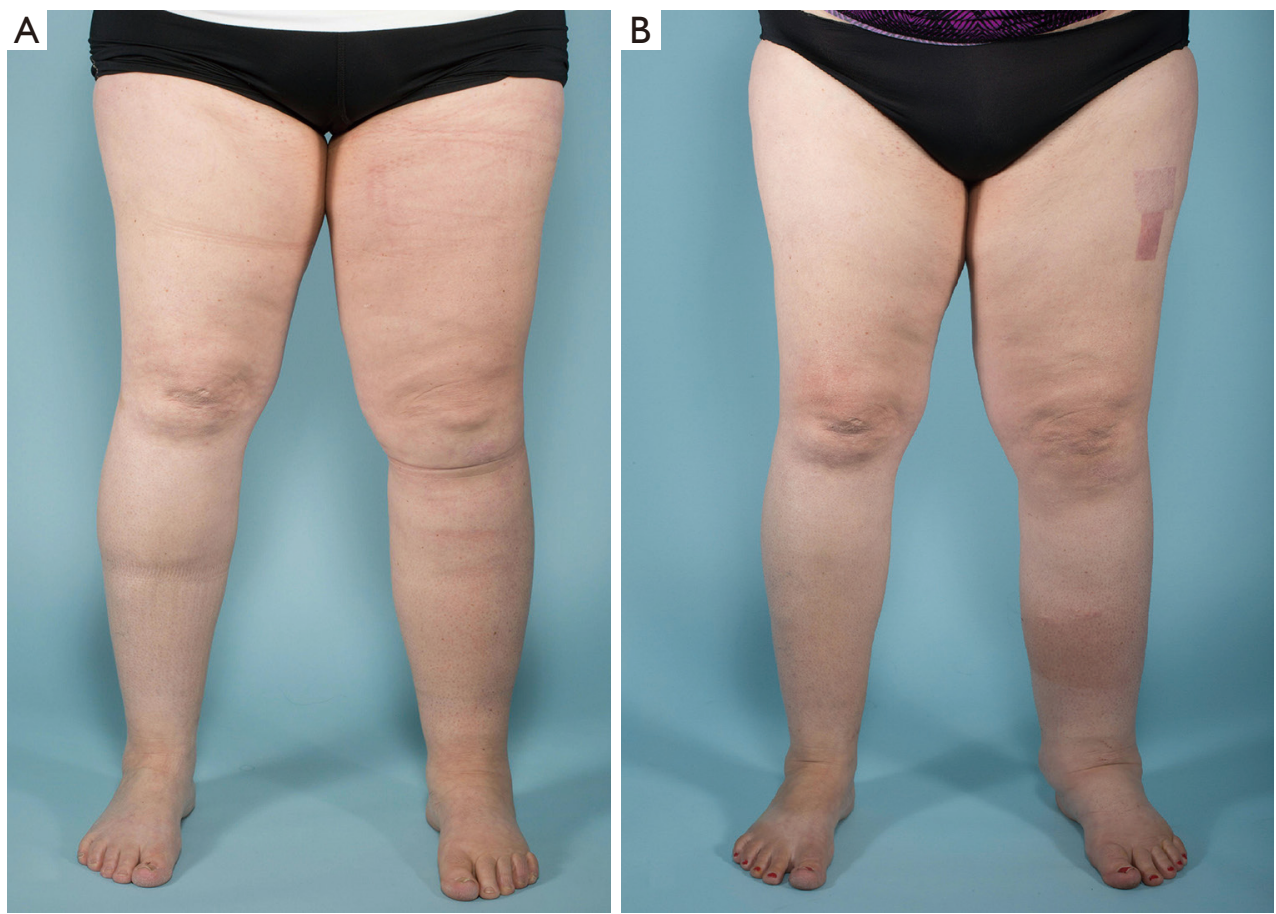

Figure 6 Medial distal inset pre and postoperatively in a 48-year-old patient with lower extremity lymphedema. (A) Preoperative; (B) 6 months postoperative shows an excess volume reduction of $16 \%$. 
Table 3 Patient-reported outcomes of patients with upper extremity lymphedema who underwent gastroepiploic vascularized lymph node flap transfer

\begin{tabular}{|c|c|c|c|c|c|}
\hline Characteristics & \multicolumn{2}{|c|}{ Middle buried $(n=7)$} & \multicolumn{2}{|c|}{ Distal $(n=7)$} & $P$ value \\
\hline \multicolumn{6}{|l|}{ Life impact (LLISv2) } \\
\hline Physical concerns & $3.4 \pm 0.5$ & $1.3 \pm 0.9$ & $3.5 \pm 0.1$ & $1.2 \pm 0.3$ & $0.05^{\alpha}$ \\
\hline Psychosocial concerns & $2.2 \pm 0.5$ & $1.5 \pm 1.1$ & $2.8 \pm 0.2$ & $1.5 \pm 0.4$ & $0.05^{\alpha}$ \\
\hline \multicolumn{6}{|l|}{ Scar } \\
\hline Satisfaction with appearance & - & $1.6 \pm 0.1$ & - & $2.6 \pm 0.3$ & $0.04^{\star \beta}$ \\
\hline Satisfaction with symptoms & - & $1.0 \pm 0.1$ & - & $2.1 \pm 0.3$ & $0.03^{\star \beta}$ \\
\hline
\end{tabular}

Data presented as mean and standard deviation. *, statistically significant; ${ }^{\alpha}$, obtained by comparing the median differences (pre and postoperatively values) for both groups using the Wilcoxon signed rank test; ${ }^{\beta}$, obtained by comparing the medians of both groups using the Wilcoxon rank sum test. LLISv2, Lymphedema Life Impact Scale-v2.

Table 4 Patient-reported outcomes of patients with lower extremity lymphedema who underwent gastroepiploic vascularized lymph node flap transfer

\begin{tabular}{|c|c|c|c|c|c|}
\hline Characteristics & \multicolumn{2}{|c|}{ Middle buried $(n=6)$} & \multicolumn{2}{|c|}{ Distal $(n=6)$} & $P$ value \\
\hline \multicolumn{6}{|l|}{ Life impact (LLIS) } \\
\hline Physical concerns & $3.3 \pm 0.3$ & $3.0 \pm 0.2$ & $3.9 \pm 0.1$ & $1.1 \pm 0.3$ & $0.84^{\alpha}$ \\
\hline Psychosocial concerns & $1.8 \pm 1.0$ & $1.4 \pm 0.5$ & $2.6 \pm 0.2$ & $0.9 \pm 0.3$ & $0.06^{\alpha}$ \\
\hline \multicolumn{6}{|l|}{ Scar } \\
\hline Satisfaction with appearance & - & $1.3 \pm 0.5$ & - & $1.9 \pm 0.1$ & $0.04^{\star \beta}$ \\
\hline Satisfaction with symptoms & - & $1.3 \pm 0.3$ & - & $1.8 \pm 0.2$ & $0.03^{\star \beta}$ \\
\hline
\end{tabular}

Data presented as mean and standard deviation. ${ }^{*}$, statistically significant; ${ }^{\alpha}$, obtained by comparing the median differences (pre and postoperatively values) for both groups using the Wilcoxon signed rank test; ${ }^{\beta}$, obtained by comparing the medians of both groups using the Wilcoxon rank sum test. LLIS, Lymphedema Life Impact Scale.

flaps $(2,32)$. These lymph node basins are favored because of their reliable anatomy and have generally demonstrated their ability to generate satisfactory outcomes. Each of these donor sites have advantages and disadvantages regarding skin paddle size, donor-site morbidity, and number of lymph nodes (3).

The GE-VLNT is the use of lymph nodes around the gastroepiploic vessels $(2,4,17,22,24,26)$. This technique is believed to be cosmetically superior, because it is able to avoid unfavorable scars through laparoscopic harvest of the lymph nodes $(14,23,24,26,33,34)$. Another advantage of GE-VLNT is the high number of transferred lymph nodes, which in several studies has been correlated to successful outcomes $(3,4,15)$. Even though other donor sites offer the possibility to be harvested along with a skin paddle, hence not requiring skin grafting the recipient site, a major concern of VLNT from other sites is the complication associated with iatrogenic lymphedema. To date, iatrogenic lymphedema has not been reported in GE-VLNT procedures (4). However, the disadvantages of GE-VLNT include longer operation time and risks of intraabdominal organ injury (14). The introduction of minimally invasive approaches, such as laparoscopic and robotic surgery to harvest GE-VLNT hold promise in reducing operator- 
induced injuries and risks associated with this surgical approach $(14,23,24)$.

There is no consensus on the best recipient site for lymph node flap transfer. Some authors argue that a distal inset (wrist or ankle) is desirable in cases of advanced lymphedema, where ascending lymph flow is greatly impaired and lymphatic flow pools with the action of gravity (35). Moreover, distal recipient sites are typically healthy and without radiation damage, whereas proximal sites (axilla or groin) are usually severely scarred due to radiation or prior surgical incisions. This makes it difficult to find adequate recipient vessels $(26,36,37)$. However, a proximal inset in upper extremities enables the release of axillary scar tissue, thus theoretically reducing venous pressure and favoring recanalization and lymphatic flow (35). A third option would be placing the lymph node flap in the volar mid-arm or the anterior mid-thigh (here referred as middle inset). This has shown to be equally effective as the distal inset, but with better aesthetics (37). A recent comparative study showed no difference between limb volume reduction and number of infectious episodes between axillary (proximal) and wrist (distal) insets (35). In fact, a recent study performed a double level inset (middle and distal placements) from a single GE-VLNT for the treatment of extremity lymphedema in order to complement the advantages of both inset sites (17).

In our experience, a significant concern for patients considering undergoing GE-VLNT with distal transfer is not only the unsatisfactory cosmetic outcome associated with recipient-site skin grafting, scarring and appearance, but also the impairment in patient's functionality during recovery. Problems with wearing footwear, long pants or long-sleeve shirts are major considerations for a distal $v s$. a more proximal placement. This gains particular relevance in regions that experience heavy winters, such as the Midwest and parts of the Northeastern coast of the United States. Furthermore, a distal inset, either in the wrist or ankle, involves greater postoperative care. This includes limb elevation, avoiding heavy exercise for at least 6 weeks and a lengthier hospital stay. On the contrary, middle lymph node flap placement, in the mid-arm or upper thigh, is more advantageous. Based on our experience, it is equally effective in limb volume reduction as a distally placed lymph node flaps. The flap is buried and no skin graft is required. Patient scar satisfaction is higher and patients are discharged 24 hours after surgery without major functional restrictions and postoperative care. A point to consider would be the inability to monitor these flaps after transfer due to the fact that they are buried under the skin. However, based on this experience, the overall functional results were similar in both groups, which in retrospect show the efficacy and safety of these transfers in the mid-portion of the limb.

This study adds to the increasing body of evidence supporting VLNT, particularly GE-VLNT, for the treatment of extremity lymphedema and delves into the recipient site options. However, it is not without limitations. Even though no major difference in patient characteristics was found between groups, formal randomization was not performed due to the fact that final inset decision was taken by the patient after a thorough discussion with the surgeon. In addition, this retrospective approach limits the patient's information to electronic medical records. Nevertheless, this comparative study paves the way to consider GEVLNT as an effective surgical option to treat extremity lymphedema and consider the different aspects between inset sites.

\section{Conclusions}

GE-VLNT is an effective surgical option for the treatment of extremity lymphedema. Based on our data, the middle buried transfer is feasible and has volume reduction comparable to distal inset; however, it may have a shorter hospital length of stay, minimal risk of complications, earlier return to work, and higher patient satisfaction.

\section{Acknowledgments}

Funding: None.

\section{Footnote}

Provenance and Peer Review: This article was commissioned by the Guest Editors (Xiaona Lu, Antonio Jorge Forte) for the series "Lymphedema" published in Gland Surgery. The article was sent for external peer review organized by the Guest Editors and the editorial office.

Conflicts of Interest: All authors have completed the ICMJE uniform disclosure form (available at http://dx.doi. org/10.21037/gs.2020.02.10). The series "Lymphedema" was commissioned by the editorial office without any funding or sponsorship. AJF served as the unpaid Guest Editor of the series. The other authors have no other conflicts of interest to declare. 
Ethical Statement: The authors are accountable for all aspects of the work in ensuring that questions related to the accuracy or integrity of any part of the work are appropriately investigated and resolved. The protocol for the research project has been approved by the Mayo Clinic Institutional Review Board (IRB No. 18-003248). The protocol conforms to the provisions in accordance with the Helsinki Declaration as revised in 2013.

Open Access Statement: This is an Open Access article distributed in accordance with the Creative Commons Attribution-NonCommercial-NoDerivs 4.0 International License (CC BY-NC-ND 4.0), which permits the noncommercial replication and distribution of the article with the strict proviso that no changes or edits are made and the original work is properly cited (including links to both the formal publication through the relevant DOI and the license). See: https://creativecommons.org/licenses/by-nc-nd/4.0/.

\section{References}

1. Schulze H, Nacke M, Gutenbrunner C, et al. Worldwide assessment of healthcare personnel dealing with lymphoedema. Health Econ Rev 2018;8:10.

2. Howell AC, Gould DJ, Mayfield C, et al. Anatomical basis of the gastroepiploic vascularized lymph node transfer: a radiographic evaluation using computed tomographic angiography. Plast Reconstr Surg 2018;142:1046-52.

3. Gustafsson J, Chu SY, Chan WH, et al. Correlation between quantity of transferred lymph nodes and outcome in vascularized submental lymph node flap transfer for lower limb lymphedema. Plast Reconstr Surg 2018;142:1056-63.

4. Mousavi SR, Akbari ME, Zarrintan S. Vascularized gastroepiploic lymph node transfer significantly improves breast cancer-related lymphedema. J Surg Oncol 2020;121:163-7.

5. Suami H, Chang DW. Overview of surgical treatments for breast cancer-related lymphedema. Plast Reconstr Surg 2010;126:1853-63.

6. Biglia N, Zanfagnin V, Daniele A, et al. Lower body lymphedema in patients with gynecologic cancer. Anticancer Res 2017;37:4005-15.

7. Abu-Rustum NR, Gemignani ML, Moore K, et al. Total laparoscopic radical hysterectomy with pelvic lymphadenectomy using the argon-beam coagulator: pilot data and comparison to laparotomy. Gynecol Oncol 2003;91:402-9.
8. Avraham T, Yan A, Zampell JC, et al. Radiation therapy causes loss of dermal lymphatic vessels and interferes with lymphatic function by TGF-beta1-mediated tissue fibrosis. Am J Physiol Cell Physiol 2010;299:C589-605.

9. Zampell JC, Yan A, Elhadad S, et al. CD4(+) cells regulate fibrosis and lymphangiogenesis in response to lymphatic fluid stasis. PLoS One 2012;7:e49940.

10. Dunberger G, Lindquist H, Waldenström AC, et al. Lower limb lymphedema in gynecological cancer survivors--effect on daily life functioning. Support Care Cancer 2013;21:3063-70.

11. Executive Committee. The diagnosis and treatment of peripheral lymphedema: 2016 consensus document of the International Society of Lymphology. Lymphology 2016;49:170-84.

12. Ciudad P, Manrique OJ, Agko M, et al. Ileocecal vascularized lymph node transfer for the treatment of extremity lymphedema: a case report. Microsurgery 2019;39:81-4.

13. Ciudad P, Yeo MS, Sapountzis S, et al. Microsurgical debulking procedure after free lymph node flap transfer. Microsurgery 2014;34:670-1.

14. Chu YY, Allen RJ Jr, Wu TJ, et al. Greater omental lymph node flap for upper limb lymphedema with lymph nodes-depleted patient. Plast Reconstr Surg Glob Open 2017;5:e1288.

15. Cheng MH, Huang JJ, Wu CW, et al. The mechanism of vascularized lymph node transfer for lymphedema: natural lymphaticovenous drainage. Plast Reconstr Surg 2014;133:192e-8e.

16. Raju A, Chang DW. Vascularized lymph node transfer for treatment of lymphedema: a comprehensive literature review. Ann Surg 2015;261:1013-23.

17. Ciudad P, Manrique OJ, Date S, et al. Double gastroepiploic vascularized lymph node tranfers to middle and distal limb for the treatment of lymphedema. Microsurgery 2017;37:771-9.

18. Ciudad P, Manrique OJ, Adabi K, et al. Combined double vascularized lymph node transfers and modified radical reduction with preservation of perforators for advanced stages of lymphedema. J Surg Oncol 2019;119:439-48.

19. O'Brien BM, Hickey MJ, Hurley JV, et al. Microsurgical transfer of the greater omentum in the treatment of canine obstructive lymphoedema. Br J Plast Surg 1990;43:440-6.

20. Goldsmith HS, De los Santos R, Beattie EJ Jr. Relief of chronic lymphedema by omental transposition. Ann Surg 1967;166:573-85.

21. Micheau P. The greater omentum. Its role in 
reconstructive plastic surgery. Ann Chir Plast Esthet 1995;40:192-207.

22. Ciudad P, Kiranantawat K, Sapountzis S, et al. Right gastroepiploic lymph node flap. Microsurgery 2015;35:496-7.

23. Ciudad P, Date S, Lee MH, et al. Robotic harvest of a right gastroepiploic lymph node flap. Arch Plast Surg 2016;43:210-2.

24. Ciudad P, Maruccia M, Socas J, et al. The laparoscopic right gastroepiploic lymph node flap transfer for upper and lower limb lymphedema: technique and outcomes. Microsurgery 2017;37:197-205.

25. Nicoli F, Constantinides J, Ciudad P, et al. Free lymph node flap transfer and laser-assisted liposuction: a combined technique for the treatment of moderate upper limb lymphedema. Lasers Med Sci 2015;30:1377-85.

26. Ciudad P, Agko M, Perez Coca JJ, et al. Comparison of long-term clinical outcomes among different vascularized lymph node transfers: 6-year experience of a single center's approach to the treatment of lymphedema. J Surg Oncol 2017;116:671-82.

27. Patel KM, Lin CY, Cheng MH. From theory to evidence: long-term evaluation of the mechanism of action and flap integration of distal vascularized lymph node transfers. J Reconstr Microsurg 2015;31:26-30.

28. Coriddi M, Wee C, Meyerson J, et al. Vascularized jejunal mesenteric lymph node transfer: a novel surgical treatment for extremity lymphedema. J Am Coll Surg 2017;225:650-7.

29. Chromy A, Zalud L, Dobsak P, et al. Limb volume measurements: comparison of accuracy and decisive parameters of the most used present methods. Springerplus

Cite this article as: Manrique OJ, Bustos SS, Kapoor T, Lin J, Ciudad P, Forte AJ, Del Corral G, Mani M, Maruccia M, Terzic A. Gastroepiploic vascularized lymph node transfer for the treatment of extremity lymphedema: comparison between middle and distal inset. Gland Surg 2020;9(2):528-538. doi: 10.21037 /gs.2020.02.10
2015;4:707.

30. Weiss J, Daniel T. Validation of the lymphedema life impact scale version 2: a condition- specific measurement tool for persons with lymphedema. Rehabil Oncol 2018;36:28-36.

31. Durani P, McGrouther DA, Ferguson MW. The Patient Scar Assessment Questionnaire: a reliable and valid patient-reported outcomes measure for linear scars. Plast Reconstr Surg 2009;123:1481-9.

32. Schaverien MV, Badash I, Patel KM, et al. Vascularized lymph node transfer for lymphedema. Semin Plast Surg 2018;32:28-35.

33. Carl HM, Walia G, Bello R, et al. Systematic review of the surgical treatment of extremity lymphedema. J Reconstr Microsurg 2017;33:412-25.

34. Ciudad P, Manrique OJ, Date S, et al. A head-to-head comparison among donor site morbidity after vascularized lymph node transfer: pearls and pitfalls of a 6-year single center experience. J Surg Oncol 2017;115:37-42.

35. Montag E, Okada AY, Arruda EGP, et al. Influência do posicionamento do retalho linfonodal vascularizado na resposta ao tratamento cirúrgico do linfedema secundário ao câncer de mama. Rev Col Bras Cir 2019;46:e2156.

36. Lin CH, Ali R, Chen SC, et al. Vascularized groin lymph node transfer using the wrist as a recipient site for management of postmastectomy upper extremity lymphedema. Plast Reconstr Surg 2009;123:1265-75.

37. Cheng MH, Chen SC, Henry SL, et al. Vascularized groin lymph node flap transfer for postmastectomy upper limb lymphedema: flap anatomy, recipient sites, and outcomes. Plast Reconstr Surg 2013;131:1286-98. 